\title{
EL ENFOQUE PROBLÉMICO TOMASINO A LA LUZ DEL SABER CÓMO PROBLEMA
}

\author{
Por: Gonzalo Camacho Vásquez ${ }^{1}$
}

\section{RESUMEN}

Se critica el enfoque problémico tomasino a la luz de la noción de saber cómo problema plateado por Gilles Deleuze. El estudio aplica la etnografía y la arqueología del saber en el análisis de los planes de asignatura de aulas virtuales de aprendizaje de los programas de pregrado. Se crean visibilidades en la manera como se entiende la noción de problema desde el tomismo y se abren interrogantes acerca de las posibilidades e implicaciones del conocimiento desde la lógica del sentido y el saber cómo patología superior.

Palabras claves: Problema, acontecimientos, Lógica del Sentido, Pensamiento como patología superior.

Clasificación JEL: Y5, Z10.

1. Magister en Educación. Pontificia Universidad Javeriana de Bogotá. Licenciado en Idiomas de la Universidad Industrial de Santander. Profesor de intercambio internacional en las escuelas públicas del condado de Pitt en Carolina del Norte (Estados Unidos). Se desempeñó como Diseñador Instruccional de la Oficina de Educación Virtual de la Universidad Santo Tomás de Bucaramanga. Actualmente ejerce como docente de la Licenciatura en Inglés de la Universidad del Tolima. 


\title{
AQUINA'S PROBLEMATIC APPROACH SEEN THROUGH THE KNOWLEDGE AS A PROBLEM
}

\author{
By: Gonzalo Camacho Vásquez
}

\section{ABSTRACT}

Aquina's problematic approach is critized by taking the notion of knowledge as a problem established by Gilles Deleuze. This study applies the principles of ethnography and the archeology of knowledge in the analysis of virtual learning rooms' subject plans belonging to the undergraduate programs at Universidad Santo Tomás de Aquino Bucaramanga. New insights in the way the notion of problem is understood from Aquinas' philosophy are created, and new questions are set about the possibilities and implications of knowledge from the Logic of Sense and thought as a superior pathology.

Key words: Problem, happenings, Logic of Sense, thought as a superior pathology.

JEL classification: Y5, Z10. 


\section{Introducción}

Es muy distinto abrir un mercado de profesiones, una demanda de trabajo calificado, que abrir un campo de pensamiento en el que la gente pueda pensar, pensar contra sí mismo, contra lo establecido, dudar, dudar de sí mismo, dudar de los que se ha creído, de los otros, de los poderosos, dudar de los débiles. Aprender y entender y no ser simplemente un especialista, una fuerza de trabajo alta o medianamente calificada (Zuleta, 2010:71).

El presente trabajo de investigación y reflexión pretende el cuestionamiento del concepto sobre "lo problémico" contenido en el discurso del Proyecto Educativo Institucional de la Universidad Santo Tomás de Aquino de Bucaramanga. Para tal propósito se utilizó el método etnográfico en la etapa de recolección y análisis de datos.

La etnográfica, tal y como lo enuncia Peter Woods (1986:102), contribuye a zanjar el hiato entre el investigador y el docente, mediante la ubicación del problema investigativo dentro del mismo problema: El término deriva de la antropología y significa literalmente "descripción del modo de vida de una raza o grupo de individuos (...) Trata de hacer todo esto desde dentro del grupo y desde dentro de las perspectivas de los miembros del grupo. Lo que cuenta son sus significados e interpretaciones".

En la recolección se partió de la conformación de un diario de campo que se iba diligenciando durante el desarrollo del trabajo de asesoría en el diseño instruccional de las aulas virtuales de aprendizaje por parte del investigador a los docentes. En la organización de la información recolectada en los datos se procedió al establecimiento de categorías, en este caso, se clasificaron las preguntas contenidas en los planes de asignatura, los cuales son la base en el diseño de las aulas virtuales.

En la etapa de construcción de las preguntas y su posterior cuestionamiento se aplicaron principios del análisis del discurso contemplado en la Arqueología del Saber y el Saber cómo problema. El propósito de este estudio, como lo enuncia la filosofía foucaultiana, no es dar respuesta o solución a un problema, sino abrir el pensamiento a partir del cuestionamiento del discurso con el fin de dejar ver nuevas visibilidades y nuevas maneras de disponer las prácticas; en este caso las prácticas pedagógicas.

La Arqueología tiene que ver con la historia de las ideas, con la manera como se han venido constituyendo los conceptos presentes en los discursos que producimos. De este modo, existen unas condiciones de aparición, institucionalización y uso determinados por causas históricas, culturales y sociales:

...la arqueología no se trata de restituir lo que ha podido ser pensado, querido, encarado o experimentado, deseado por los hombres en el instante mismo en que proferían el discurso (...) No es nada más y ninguna otra cosa que una reescritura, es decir, en la forma mantenida de la exterioridad, una transformación pautada de lo que ha sido y ha escrito. No es la vuelta al secreto mismo del origen, es la descripción sistemática de un discurso-objeto (Foucault, 1983: 227). 


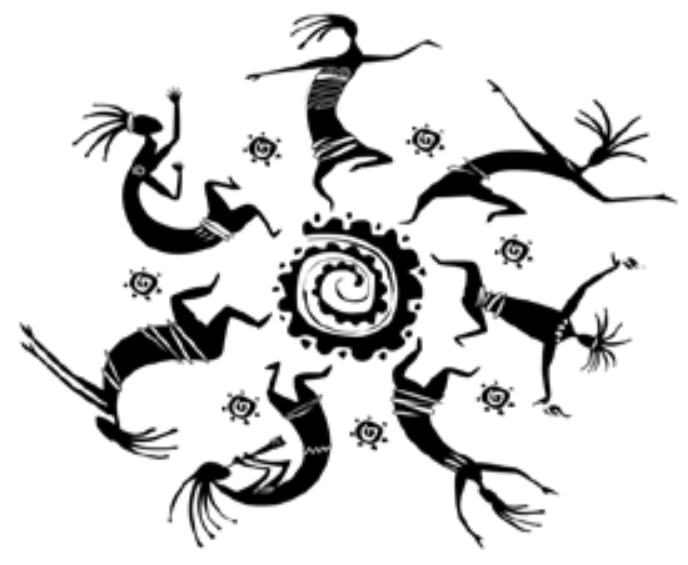

Imagen en línea, obtenido de shutterstock.com. Derechos de autor Viktoria.

\section{De lo problémico}

La misión de la Universidad Santo Tomás se concibe en el Proyecto Educativo Institucional como la de promover la formación integral de las personas, mediante acciones y procesos de enseñanza-aprendizaje, investigación y proyección social, para que respondan de manera ética, creativa y crítica a las exigencias de la vida humana y estén en condiciones de aportar soluciones a la problemática y necesidades de la sociedad y del país (Universidad Santo Tomás, 2004:20-35).

De este modo, el enfoque problémico Tomasino se erige como una de las justificaciones a los componentes de esta misión en lo que respecta a soluciones a la problemática y necesidades de la sociedad del país. En este primer aspecto de la definición del enfoque existe un vínculo entre problema y solución lo cual sesga la función de la pregunta a las condiciones de la necesidad. Es decir, el pensamiento actúa en los límites de la satisfacción de la necesidad, lo que impide nuevas visibilidades, nuevas manera de ver la relación entre los conceptos contenidos en el cuerpo de la pregunta. Esta disposición de problemas parece contradecir las posturas de la Lógica del Sentido al respecto. Para la Lógica del Sentido, como lo advierte Alejandra Lichillín (1999:10), el problema no se encuentra dado en una realidad empírica (como es la satisfacción de una necesidad), no está en un constructo teórico oracional, sino que el problema se construye. Cada uno de nosotros debe construir un propio problema, de lo cual habría que deducir que el conocimiento se construye a partir de los problemas que fabricamos.

El Proyecto Educativo puntualiza respecto a lo problematizador, enfatiza que lo que es "problematizador" es el método, que avanza por conjuntos articulados de problemas (problemáticas), como acostumbra a hacer Tomás de Aquino con los artículos de cada "cuestión” problematizadora de la Suma Teológica (Universidad Santo Tomás, 2004: 34). 
Analizando el tipo de preguntas presentes al inicio de cada uno de los artículos de la Suma Teológica (Primera Parte, cuestión 2), encontramos que la mayoría de las preguntas conducen a una respuesta que está entre la dicotomía del "si" o el "no" ¿Qué efecto logran este tipo de preguntas? Generalmente conducen a una demostración de una postura particular dependiendo de si se quiere negar o afirmar los conceptos contenidos en la pregunta:

Lo primero plantea y exige respuesta a tres problemas:

1. ¿Es o no es evidente Dios por sí mismo?

2. ¿Es o no es demostrable?

3. ¿Existe o no existe Dios?

De hecho, lo que provoca la pregunta en la Suma Teológica es una demostración rigurosa regida por el método tomista, el cual expone argumentos en contra, argumentos a favor, prueba de tesis y solución de las obječiones. Como lo enuncia Beuchot (2004:25), el pensamiento tomista, influenciado por Aristóteles, se mueve en la dinámica del ser (potencia) y el deber ser (acto). Así, el conocimiento lo plantea como una especie de virtud a la que hay que llegar:

...en el sistema del Aquinate, todo se estructura con base en esta dualidad de aspectos ontológicos: lo que está en acto y lo que está en potencia (o en acto pero mezclado de potencia). Todo lo que es potencia tiende al acto y se desarrolla hacia él; y lo que tiene más acto es más perfecto que lo que está en potencia. Al mismo tiempo, lo que de potencia hay en un ente sirve de limitación a lo que en él hay de acto. De esta manera todo el sistema tomista se nos muestra como un "dinamismo energético" en el que lo que esté en potencia tiende y se ordena a lo que está en acto, o a alcanzar su propio acto (...) se trata de un orden analógico o de jerarquía, en donde lo más perfecto es lo que más está en acto y lo más imperfecto es lo que más está radicado aún en la potencia.

Este pensamiento en donde el conocimiento se plantea como un fin a alcanzar a través de un sistema jerárquico y organizado contrasta con el pensamiento como patología superior planteado por Gilles Deleuze (1988:112). Según lo expresa el autor en Diferencia y Repetición, el saber pertenece a un pensar sin presupuestos:

Si esto fuera cierto, la imagen de pensamiento que Deleuze vendrá a proponernos podría caracterizarse como en abierta hostilidad hacia lo normal, contraria a la decisión de elevar lo normal a lo normativo-como un ejercicio intempestivo de demolición de lo que todo el mundo sabe, de lo que nadie puede negar...pensar sería antes acontecimiento que reconocimiento. Pero, sobre todo, pensar sería búsqueda de lo que sólo puede ser pensado: insistencia en lo que nos fuerza a pensar. Entonces, deberíamos decir, si el pensar se abre a la exterioridad de lo real, si el pensar recorre el mundo, es para medirse con lo impensable. 


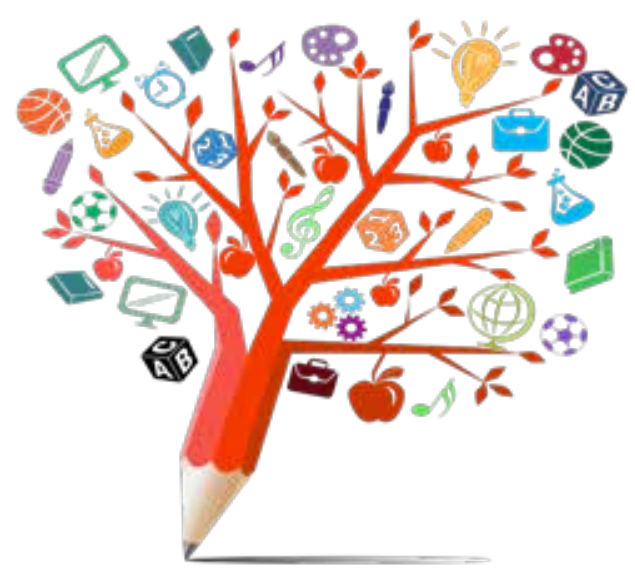

Imagen en línea, obtenido de shutterstock.com. Derechos de autor tanewpix.

De esta manera, el pensamiento, y por ende el conocimiento, se encuentra fuera de la idea de lo organizado, no es algo que está por descubrirse, a modo de acto en Santo Tomás de Aquino; por el contrario, está por construirse, tiene esencia en su propia construcción a partir de su contradicción. No existiría el conocimiento como algo a lo cual debemos llegar y se encuentra preconcebido. El saber es caótico, impredecible, impensado, tiene sentido en la diferencia y no en la repetición.

Si bien el tipo de concepción respecto al pensamiento problémico en la filosofía tomasina logra en primera instancia que haya una apropiación del conocimiento en cuestión como principio de la argumentación, estaría lejos de la visión del pensamiento como problema desarrollado por Gilles Deleuze. Este pensador francés sostiene que el problema tiene un carácter productivo esencialmente afirmativo. Se aparta de las consideraciones que relacionan al problema con el obstáculo, la carencia o la necesidad. El problema sería el espacio-tiempo del pensamiento asumido como una fuerza del afuera. Para Deleuze, un problema no expresa una incertidumbre subjetiva, sino, por el contrario el equilibrio objetivo de un espíritu situado ante el horizonte de lo que acontece o aparece ahí, en cada distribución de singularidades; el problema no es una oposición, reacción o respuesta sino la creación de un nexo con el horizonte en el que "algo" acontece.

¿Qué significan estas observaciones? Que el problema no es un obstáculo que hay que rebasar, tampoco es una necesidad a la que hay que atender; el problema no surge del interior del individuo sino que pone en relación el deseo, la intuición de quién trabaja con un universo conceptual. Esta conexión hace que el trabajo investigativo venga del afuera y no se quede como un mero dilema subjetivo. Luego entonces, ¿cómo se construiría una pregunta problemática según la Lógica del Sentido?

Para Deleuze, el problema tiene tres componentes: las ideas, los acontecimientos y las preguntas. A la vez, las ideas están compuestas por imágenes y conceptos. 


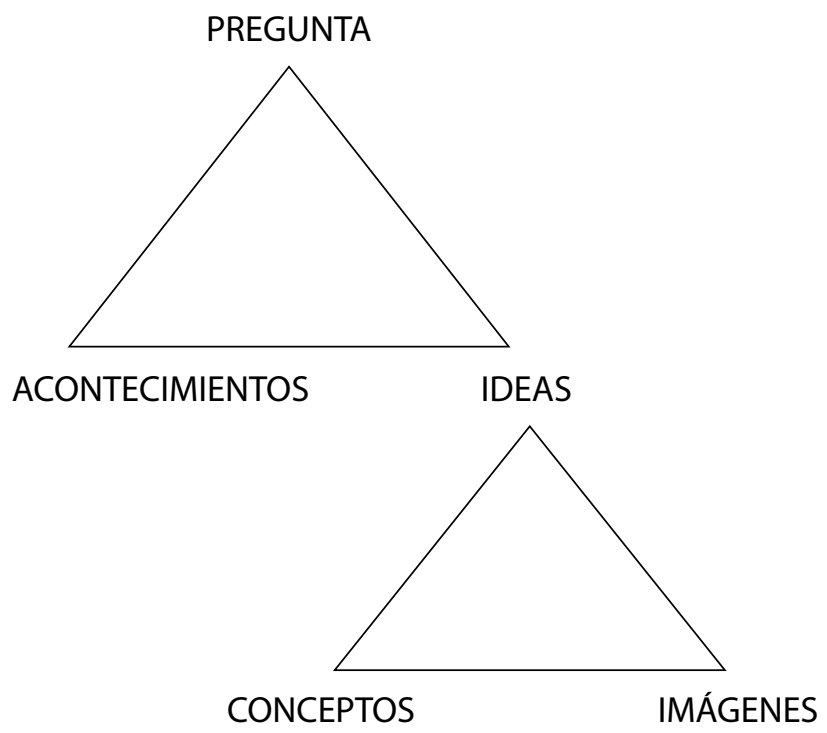

Así la pregunta, o mejor dicho la serie de las preguntas, surge del entrecruce entre la serie de las ideas y la serie de los acontecimientos. Las ideas son el componente efectivamente problemático, surgen de los conceptos definidos como productos discursivos con una carga de significado que nos remiten a las imágenes. A la vez las imágenes se concretizan en los conceptos que funcionan como cuerpo de éstas. En otras palabras, las imágenes existen cuando se concretizan en los conceptos, y los conceptos solo existen porque nos remiten a las imágenes. De este modo, como lo demuestra Michel Foucault en "Historia de la Sexualidad" un concepto como "el cuidado de sí mismo" puede sufrir diferentes transformaciones correspondientes a diferentes imágenes. El "le souci de soi” o "el cuidado de sí" de los griegos, el cual implicaba una idea estética de belleza y salud, pasa al cristianismo como "control de sí", lo cual implicaba la idea de vigilancia a través de la confesión:

...la confesión es un ritual de discurso en el cual el sujeto que habla coincide con el sujeto del enunciado; también es un ritual que se despliega en una relación de poder, pues no se confiesa sin la presencia al menos virtual de otro, que no es simplemente el interlocutor sino la instancia que requiere la confesión, la impone, la aprecia y la interviene para juzgar, castigar, perdonar, consolar, reconciliar (Foucault,1983: 55).

De este modo, lo que en un principio para los griegos era un asunto estético, se convierte en una cuestión ética para los cristianos. Esta relación entre conceptos e imágenes se convierte en un juego discursivo que nos lleva a establecer las tensiones entre los dos al interior de las preguntas.

El análisis de las ideas presentes en el cuerpo de las preguntas nos lleva a hacer una "arqueología" discursiva mediante el rastreo de los conceptos y las imágenes que las definen. Este rastreo nos permite establecer las condiciones de aparición 
de las ideas en determinados periodos históricos conectando con los hechos sociales, políticos, económicos entre otros, que provocaron su aparición. Los grandes acontecimientos históricos de la humanidad provocaron la aparición de nuevas ideas y con ello nuevos productos discursivos. Esta especie de ontología del saber nos lleva a establecer el origen de las ideas, y es lo que nos permite posteriormente hacer conexiones de estas con los diferentes campos del saber.

Luego entonces, un concepto puede, a través de la historia, sufrir plegamientos que lo llevan a desaparecer y desplegamientos que lo llevan a re-surgir con el mismo o diferentes sentidos. Continuando con el concepto de "cuidado de si", anteriormente mencionado, podríamos conectarlo con la idea de belleza inicialmente dada por los griegos. En la Edad Media, el cuidado de sí se convierte en una cuestión ascética, de pureza, de acercamiento a la idea de Dios y genera dispositivos de sujeción (poder sobre los sujetos) en la figura de la confesión, lo que Michel Foucault denomina "tecnologías del yo". Para Freud en su teoría del psicoanálisis, el "cuidado de si" estaría en el campo de lo clínico definiendo técnicas para "hacer hablar" y se enmarcaría dentro del círculo del conocimiento científico. Como tal sería efecto del método para describirlo.

Así la idea de cuidado estaría directamente conectada con la idea de "comportamiento" o "conducta" del ser basados en el análisis de sus procesos mentales. Para Lev Vigotsky, "el cuidado de si" estaría relacionado con la idea de "desarrollo de la autonomía" en sus procesos ontogenéticos. Díaz, Neal and Amaya-Williams puntualizan respecto a los orígenes sociales de la autoregulación planteada por Vigotsky (Díaz, Neal, Amaya-Williams, 1990: 128): In developmental psychology, the capacity of self-regulation appears as a central organizational construct in both cognitive and social development. Cognitive advances in the school years, for example, are marked by increased "executive control" (Stenberg, 1984) and self-regulation of perceptual, attentional, and memory process.

De este análisis nos quedan las siguientes preguntas:

¿Qué efectos se produce cuando la pregunta se vincula a las ideas o cuando la pregunta parte del análisis de las ideas?

¿Es este ejercicio una manera de construir conocimiento mediante la conexión entre las diferentes disciplinas del saber?

\section{Análisis del componente problémico en los planes de asignatura}

Pasemos ahora a hacer el estudio de la serie de la ideas en preguntas tales como las que se presentan en algunas aulas virtuales diseñadas en la plataforma Moodle. Para efectos de la investigación, éstas fueron escogidas a través del trabajo de observación realizado como parte de la asesoría a los docentes de la Universidad por el autor del artículo. Se siguieron las indicaciones del método etnográfico a través del registro escrito en diarios de campo. El uso de esta herramienta permitió consignar eventos observados y paralelamente comentarios surgidos durante y después de la observación. 


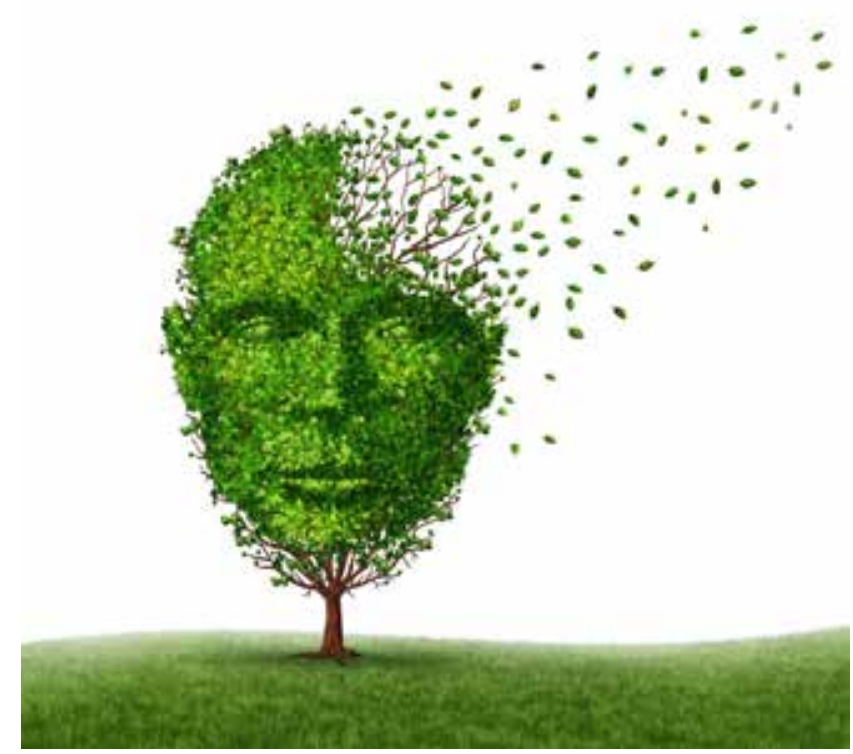

Imagen en línea, obtenido de shutterstock.com. Derechos de autor lightspring.

Empecemos por examinar el aula virtual de educación ambiental. Lo primero que haría la lógica del sentido sería establecer las imágenes al interior de los conceptos puestos en juego en la pregunta. Para la pregunta: ¿Reconoce el individuo la necesidad de una educación ambiental como un compromiso propio con la sociedad?

El punto de inicio estaría en dudar de la relación de cada concepto consigo mismo y la relación entre conceptos en el limbo de la paradoja:

¿Qué imagen se tiene de "educación ambiental”?

¿Desde cuándo se empezó a hablar de educación ambiental?

¿De qué se hablaba antes de hablar de educación ambiental?

¿Es lo ambiental una cuestión de educación?

¿Qué se logra cuando el individuo reconoce la necesidad de una educación ambiental?

¿Es necesario que el individuo reconozca la necesidad de una educación ambiental?

Con este tipo de preguntas logramos darle la vuelta a los conceptos y las imágenes y nos lleva a ver lo que la pregunta dialéctica no nos deja ver. Pero la pregunta no solo se relaciona con las imágenes y los conceptos contenidos en las ideas, sino que también establece un vínculo con la serie de los acontecimientos. Estos son todo lo contrario a lo que acontece normalmente como producto de la rutina. Tiene relación con el deseo del individuo, es aquello que le genera atracción y que lo 
saca de lo rutinario para ponerlo en una singularidad, en un giro, en un cambio, en un retroceso, en un punto sensible. Tomando las ideas de Baruch Espinosa, el acontecimiento es lo más cercano a aquello que nos afecta a la manera como el sol deja huella en la piel.

El acontecimiento necesariamente nos debe llevar a visibilizar nuevos órdenes, nuevas maneras de ser y de concebir la realidad. El acontecimiento en la pregunta vincula las ideas llevándolas a una nueva postura, una nueva visibilidad que rompe con el esquema de lo tradicional para abrir el pensamiento con una propuesta, otra disposición, otro orden.

¿Qué pasaría si lo ambiental se viera más allá del marco de lo educativo?

¿Cómo sería hacer de lo ambiental un modo de vida?

¿Qué de la cátedra tradicional impide una verdadera conciencia ambiental?

¿Qué procedimientos, constructos teóricos, habitualizaciones y concepciones van en contravía de una conciencia ambiental?

Este tipo de preguntas permite ser realmente problemático al llevar a relacionar las ideas con acontecimientos que en últimas se convierten en propuestas que abandonan las indagaciones por dialécticas y pone el pensamiento en función constructiva. La última pregunta planteada en el párrafo anterior, nos llevaría a propuestas en las que lo ético transgrede lo estético al poder proponer por ejemplo que la costumbre de planchar la ropa contribuye al calentamiento global. Así una "Educación ambiental" iría más allá de comprender las causas y consecuencias de la destrucción del planeta para plantear estrategias concretas que logren afectar nuestra relación con éste.

En una Lógica del Sentido, las preguntas no estarían dadas por el docente en el plan de asignatura. Las preguntas no serían el punto de partida, sino una ruta de llegada. Llegada que aparecería incierta al no poder prever las intenciones, los deseos, las afectaciones que sufrirá el estudiante al enfrentarse a las teorías. Al respecto dice Alejandra Lichilín (1999: 10): entre el problema y su solución media un espacio que es necesario recorrer. Si se plantea que la solución es inherente al problema mismo, el método deja de ser un recorrido para constituirse en una forma inmediata de pensar y conocer, es decir, una forma de ver la vida que contiene la energía de la intuición inicial y novedosa.

¿Qué tipo de preguntas encontramos en los planes de asignatura?

Encontramos 3 tipos de preguntas, los cuales analizaremos a continuación.

\section{Preguntas de procedimiento}

¿Cómo ha evolucionado el sistema económico mundial?

¿Cómo medir los efectos de las finanzas internacionales en la economía? 
¿Cómo instruir a los padres en las técnicas de higiene oral a utilizar para prevenir la caries y la enfermedad periodontal?

¿Cómo motivar a los niños para el aprendizaje de los hábitos de higiene oral?

¿Cómo se aplica la normatividad aduanera en las operaciones del comercio internacional?

¿Cómo ser líderes en la preservación de la naturaleza desde nuestra Facultad?

\section{Preguntas de demostración o argumentación}

¿El saber ancestral es especulación o sabiduría?

¿Un profesional que promueve la honradez puede ser exitoso?

¿Por qué es importante estudiar estadística en los negocios internacionales?

\section{Preguntas de descripción}

¿Cuáles son los aportes que desde las profesiones contribuyen al desarrollo del pensamiento humano y científico como pilares transformadores de la realidad?

¿Cuál es la incidencia de la rentabilidad del activo en la generación de valor para la empresa?

¿Cuáles son los elementos que conforman el Flujo de Caja Libre?

¿Cuáles son las principales características anatómicas de la cámara pulpar y los conductos radiculares?

Al clasificar un grupo de preguntas tomadas de quince planes de diferentes asignaturas utilizando como herramienta el diario de campo, se pudo apreciar que la mayoría de estas preguntas pretende indagar por un procedimiento, una técnica o una manera de realizar un proceso. Otro grupo de preguntas se preocupa por demostrar el conocimiento, y otro por describir, lo que en últimas se logra mediante manejo conceptual. Estos tres grupos de preguntas estarían en el orden de atender a la demanda de mano de obra calificada para desempeñar labores del mercado tal y como lo enuncia Estanislao Zuleta. En otras palabras, el objeto del conocimiento en estas preguntas es la apropiación conceptual y teórica. Aquí el conocimiento se concibe como un producto terminado, del cual solo se debe aprehender. Estas preguntas parecieren no disponer el aprendizaje hacia la construcción del saber, sino más bien satisfacer las necesidades del medio. Cabe preguntarse en esta instancia:

¿Será que el fin último de la educación es "solucionar problemáticas de la sociedad"?

¿Es solucionando problemáticas concretas como se hace investigación? 
¿Cómo se puede llegar a descubrir otra manera de, otros dispositivos, si las preguntas no dudan del conocimiento y lo asumen como algo que simplemente se debe adquirir?

¿La mayoría de los descubrimientos científicos surgieron por la preocupación de satisfacer una necesidad, o a partir del cuestionamiento, duda o crítica de las leyes y postulados teóricos?

¿Cómo llegar a descubrir algo nuevo sin dudar de los conceptos y preceptos existentes?

¿Es la solución a los problemas y las necesidades un resultado de los descubrimientos?

Alexander Flemming parecía no ser consciente de crear una solución para tratar las infecciones. El descubrimiento de Fleming viene completamente por accidente cuando se da cuenta de que el moho ha matado a una muestra de bacterias en una placa de Petri que languidece bajo una pila en el fregadero de su laboratorio. Sin embargo, muy seguramente no hubiese llegado a su descubrimiento si no tuviera el deseo de experimentar. Charles Darwin no hubiese podido publicar "El Origen de las Especies Mediante la Selección Natural", sino hubiese dudado y desafiado las creencias acerca de la creación de la vida en la Tierra. Wilhelm Roentgen descubre accidentalmente los rayos $\mathrm{X}$ al realizar experimentos con la radiación de rayos catódicos (electrones). Se da cuenta de que los rayos pueden penetrar en papel negro opaco envuelto alrededor de un tubo de rayos catódicos, causando una forma que brilla con fluorescencia. Su descubrimiento revoluciona la física y la medicina, lo que le valió el primer Premio Nobel de Física en 1901.

Es este hecho de experimentar y dudar el que está presente en el acontecimiento enunciado por Deleuze. Se trata de crear nuevas visibilidades a partir de la duda y el cuestionamiento de lo rutinario o de lo que comúnmente se concibe como dado o terminado. El saber no es un acto necesariamente planeado. Surge de lo fortuito, del acto mismo de construcción, sin intención cegada por el resultado.

\section{Conclusiones y retos}

De acuerdo a lo expuesto, nos quedan los siguientes cuestionamientos que nos podrían guiar hacia el desarrollo concreto de estructuras de pensamiento que logren vincular el conocimiento más con su naturaleza inquisitiva hacia propuestas reales de cambio, con el fin de satisfacer necesidades vistas como carencia u obstáculo y cuya satisfacción limita la construcción del saber:

¿Tienen nuestros estudiantes la opción de experimentar, de realizar movimiento de piezas que los lleven a ver nuevas maneras de concebir el mundo?

¿Qué pasaría si tomáramos el conocimiento a modo de experimento, a modo de acontecimiento? 
¿Qué efecto producirían en el área del derecho preguntas como: ¿Es función del abogado aprender la ley y aplicarla, duplicando el statu quo de la democracia?

¿Es posible cuestionar el orden democrático?

¿Se puede experimentar dudando de la democracia para crear nuevos modos de gobierno? En otras palabras, ¿Es posible pensar lo in-pensado?

A nivel del plan de estudios:

¿Qué ajustes es necesario hacer con el fin de vivenciar el enfoque problémico?

¿Qué se debe hacer para que lo problémico deje de ser una manera discursiva y se convierta en una práctica?

Esta pregunta necesariamente nos lleva al plano del diseño de experiencias de aprendizaje. Si Foucault afirma que no solo producimos discursos, sino que somos producto de un discurso; entonces podríamos aseverar que para que cambien las prácticas pedagógicas se deben cambiar los discursos que las determinan. De este modo, la investigación debería estar encaminada menos hacia lo estadístico y a estudios que buscan comprobar o justificar los órdenes pre-establecidos para entrar en un ejercicio de armado y desarmado de los dispositivos pedagógicos mediante la crítica.

Un ejemplo de la manera cómo se puede atar el discurso a la práctica en cuanto a filosofías educativas lo constituye el PPI o Paradigma Pedagógico Ignaciano (Comunidad Jesuita, 2002:12-21).

La pedagogía Jesuita aplica la metodología de los Ejercicios Ignacianos apelando a los 5 momentos descubiertos por Iñigo López para descubrir a Dios en su vida. Estos son: La contextualización: En este momento se exploran los pre-saberes del aprendiz, se relaciona el saber nuevo con el previo y se establece su relevancia. La Experiencia: Se descubre, se construye el saber poniendo en juego los cinco sentidos. La Reflexión: Se analiza, se discierne acerca de la comprensión del conocimiento construido mediante preguntas. La acción: Se establece una aplicación concreta del saber en el mundo circundante. Finalmente la evaluación es una especie de estrategia metacognitiva en la que el aprendiz evalúa su desempeño y señala líneas de acción para futuras experiencias.

¿Cómo luciría un intento por vincular la filosofía tomista en el ejercicio pedagógico?

Este intento indispensablemente debe contener nuevas maneras de concebir la práctica a partir de los contextos educativos.

Si bien es cierto que el pensamiento tomista introdujo aportes significativos a la manera de pensar en su época, ¿sería posible renovarlo en nuestros tiempos a partir de su propia contradicción? 
¿Qué tipo de sociedad perpetúa la reproducción de un pensamiento que alimenta las necesidades laborales?

¿Es nuestra esencia humana la de contribuir a un modelo productivo e industrial que educa en el consumismo llevando a la destrucción de nuestro planeta?

$\mathrm{Al}$ respecto, Michel Foucault habla del bio-poder, el cuál propende el control del cuerpo para satisfacer los intereses del sistema. Los diferentes perfiles de las instituciones educativas buscan la formación de un "ser integral". La integralidad se resume en el amoldamiento de un ser que se ajuste a las necesidades del medio ${ }^{2}$.

Finalmente: ¿Qué cambios introduciría la noción de problema en el saber, no como solución, sino como patología superior? ¿Qué pasaría si el saber es pensado fuera de la idea de orden, de organización y estratificación para concebirlo como caótico, creativo, problemático?

La relación con el saber pasaría a ser de afectación, movida por el deseo, por la curiosidad, por las "ganas" de aprender, de construir, de armar, de desarmar. En otras palabras, sería un juego. Pareciere obvio que dentro del mismo conocimiento existen líneas duras que requieren de un orden, de una exactitud, esto en el caso del saber científico; sin embargo, como seres humanos siempre debe haber cabida para la creación, la duda, la intuición. La labor del investigador sería la de buscar resquebrajamientos en estas líneas duras para crear fisuras que lleven a flexibilizar los procesos, los dispositivos, las disposiciones o los paradigmas.

2. El autor analiza la Formación integral en la Universidad Santo Tomás en el artículo: Camacho, G (2012). El Pensamiento Rizomático en la Construcción de un modelo didáctico que vivencie la Formación Integral en el esquema de Educación Virtual de la Universidad Santo Tomás de Bucaramanga. Espiral Revista de Docencia e Investigación, 2- 2, 91-102. 


\section{Referencias}

BEUCHOT, Mauricio (2004). Introducción a la filosofía de Santo Tomás de Aquino. Salamanca: Editorial San Esteban.

CAMACHO, Gonzalo (2012). El Pensamiento Rizomático en la Construcción de un modelo didáctico que vivencie la Formación Integral en el esquema de Educación Virtual de la Universidad Santo Tomás de Bucaramanga. Espiral Revista de Docencia e Investigación, 2- 2, 91-102.

COMUNIDAD JESUÍTA (2012). PEDAGOGÍA IGNACIANA. Un planteamiento Práctico. (En línea). Disponible en: http://www.sjweb.info/documents/education/pedagogy_sp.pdf. (Consultado: Marzo 10.2014)

DELEUZE, Gilles (1988). Diferencia y Repetición. Capítulo: La imagen del pensamiento. Madrid: Editorial Júcar Universidad.

blemático" Barcelona: Editorial Paidós Studio:

DIAZ, NEAL Y AMAYA-WILLIAMS. The social origins of Self-regulation. En: Moll, Luis (1990) Vigotsky and Education. Instruccional Implications and applications of Sociohistorical Psychology. New York: Cambridge University Press.

FOUCAULT, Michel (1983). Historia de la Sexualidad. Tomo I Capítulos III y IV. En:Wiesner, Santiago. El Saber cómo Problema (pp. 48-105), Bogotá D.C: Javegraf.

(1983). La Arqueología del saber. México: Editorial Siglo XXI,

LICHILIN, Alejandra (1999). Presentación Módulo: La construcción del Problema y la Lógica del Sentido. Maestría en Educación. Campo de Profundización en Educación para la Convivencia. Bogotá D.C. Javegraf

SANTO TOMÁS DE AQUINO (1225-1274). Suma Teológica. Parte I, cuestión 2: Sobre la Existencia de Dios. Disponible en: http://hjg.com.ar/sumat/index.html. (Consultado Marzo 10-2014)

UNIVERSIDAD SANTO TOMÁS DE AQUINO (2004). Proyecto Educativo Institucional PEI. Tercera Edición. Bogotá D.C: Universidad Santo Tomás. Páginas 20-35.

VIGOTSKY, Lev (1978). Mind in Society: the development of higher psychological processes. Cambridge, MA: Harvard University Press.

WOODS, Peter (1986). La Etnografía en la Investigación educativa. En: La Escuela por Dentro. Temas de Educación. Barcelona: Editorial Paidós.

ZULETA, Estanislao (2010). Educación y Democracia. Un campo de Combate. OMEGALFA. Biblioteca Virtual. Disponible en: file:///C:/Users/MASTER/Downloads/educacion-y-democracia.pdf. (Consultado Marzo 20, 2014). 